\title{
Fabrication of Solar Water Distillation
}

\author{
Deepak Kumar \\ Non-conventional resources Laboratory, Department of Mechanical \\ Collage of science and Engineering, Jhansi, India \\ Pushpendra Kumar \\ Non-conventional resources Laboratory, Department of Mechanical \\ Collage of science and Engineering, Jhansi, India
}

\begin{abstract}
The most important aspect for sustaining life on earth is water. In spite of its abundant availability small percentage can be used for drinking purpose (approximate 1\%). The solar water distillation comes out to be a nontoxic and promising device which purifies water that uses a renewable solar energy source, Efficiency of the solar water distillation device can be enhanced by increasing evaporation rate that is a combined effect of solar radiation, cover glass temperature, water contamination density, base plate absorptive and provide additional heat by solar water preheating system.
\end{abstract}

\section{INTRODUCTION}

Water is the basic necessity for human along with food and air. There is almost no water left on Earth that is safe to drink without purification. Only $1 \%$ of Earth's water is in a fresh, liquid state, for the need of the plants, animals and human life.

This water is reducing day by day continuously and this $1 \%$ water is available in rivers, lakes, and underground reservoir. This ground water has also been polluted due to industries, agricultural and population growth during the current year. Polluted water causing Sevier diseases like "water borne diseases". The term "water borne diseases" is reserved largely for infections that predominantly are transmitted through contact with or consumption of infected water. And water borne diseases is affecting human health; nearly 70-75\% diseases have infected water in India. The world is facing the scarcity nearly all of this is polluted by both diseases and toxic chemicals. For this reason, purification of water supplies is extremely important. Moreover, typical purification systems are easily damaged or compromised by disasters, natural or otherwise. This results in a very challenging situation for individuals trying to prepare for such situations, and keep themselves and their families safe from the myriad diseases and toxic chemicals present in untreated water. Everyone wants to find out the solution of above problem with the available sources of energy in order to achieve pure water. Fortunately there is a solution to these problems. It is a technology that is not only capable of removing a very wide variety of contaminants in just one step, but is simple, cost-effective, and environmentally friendly. That is use of solar energy.

Contaminated drinking water is one of the reasons of major health hazards responsible for almost $90 \%$ of the health problems in rural areas. Women and children are mostly affected because they are quite vulnerable to water borne diseases. Generally, women are responsible for fulfilling the requirement of water in their household and thus, spend their large chunk of time for procuring the same. Out of 40-50 liters per capita per day (lpcd) of water requirement for domestic consumption, only 2 lpcd is the drinking water.

A total amount of5-10 lpcd water is needed for drinking and cooking purposes and thus, it is only this quantity of water that needs to meet the stringent quality standards of portability prescribed by W.H.O. or other similar agencies, whereas the remaining amount of water needed for washing and cleaning can be of intermediate quality.

Intensive use of chemical fertilizers in agriculture and enhanced Industrial activities cause the natural and inorganic pollutants to leach down to underground sub surface water and hence, the drawing of water through Hand-Pumps may not remain safe for drinking purpose. Keeping in view the poor paying capacity of people, water supply to remote areas through pipeline could be uneconomical and moreover, it also 


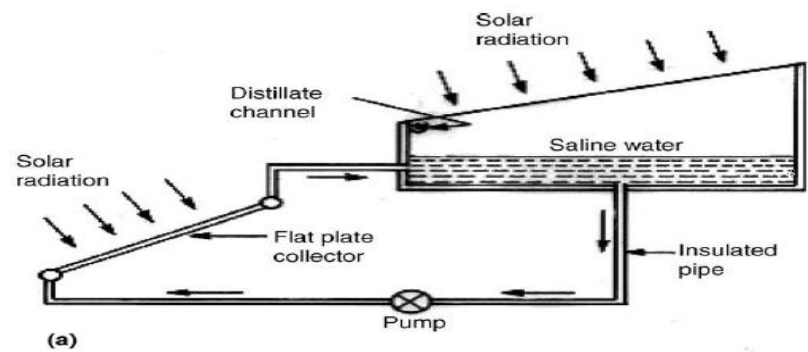

(a)
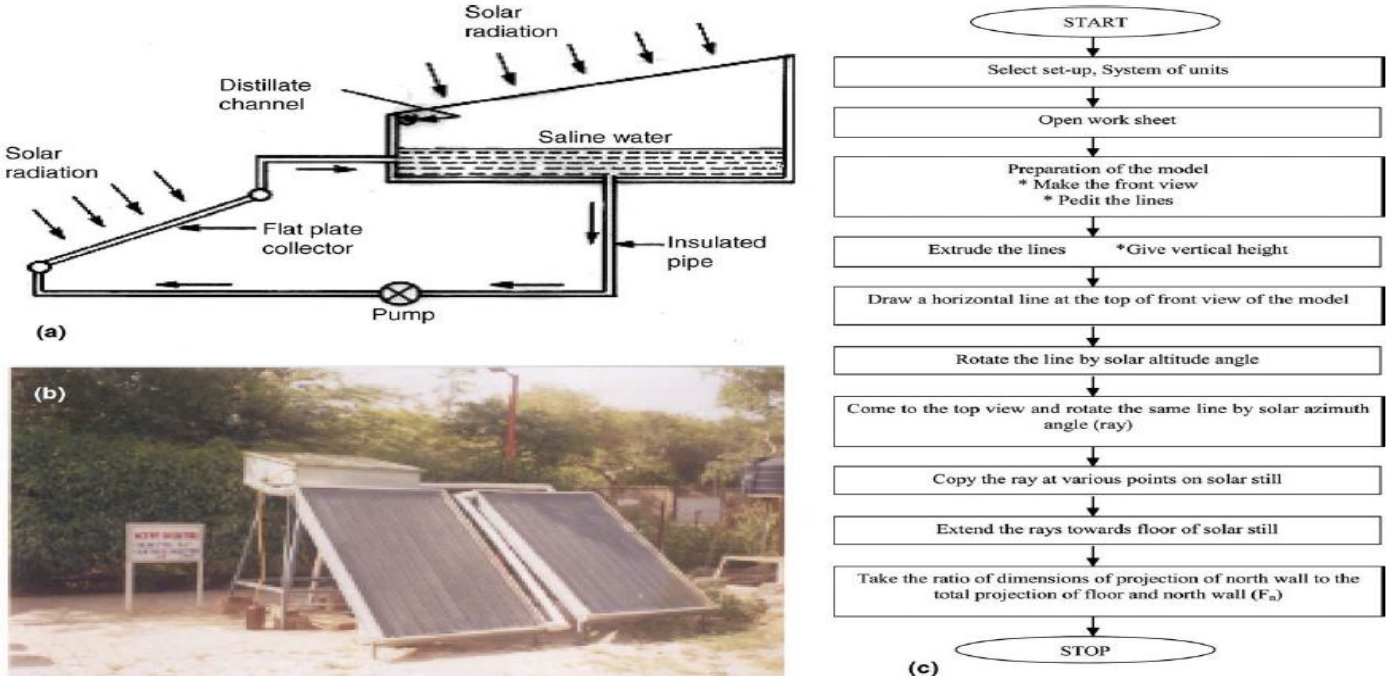

encourages wasteful use of high quality water in washing, cleaning and toiletries.

\section{Figure1.Schematic diagram of an active solar still coupled with a flat plate collector, (b) photo graph of the experimental set-up and (c) flow chart of the AUTOCAD 2000 model}

Therefore, for economical and sustainable water management system, it is important to supply water at appropriate level of quality, which is suitable enough for the kind of use for which it is meant water and energy are two inseparable items that govern our lives and promote civilization. Looking into the history of mankind one finds that water and civilization were also two inseparable entities. It is not a coincidence that all great civilizations were developed and flourished near large bodies of water. Rivers, seas, oases and oceans have attracted mankind to their coasts because water is the source of life. The transportation of drinking water from far-off regions is usually not economically feasible/ desirable, desalination of available brackish water has been considered as an alternative approach. Conventional desalination processes based on distillation involve phase change. These are multistage flash distillation.

\section{EXPERIMENTAL SETUP}

Construction of Solar Still: The base of the solar still is made of G.I. box of dimension (4' x 2' x $10 \mathrm{~cm}$ ). This box is embedded into box of G.I. shown in figure 1 . Here length $\mathrm{L}=60 \mathrm{~cm}$, Breath $\mathrm{B}=75 \mathrm{~cm}$, Height $\mathrm{H}=38 \mathrm{~cm}$. and at opposite side $=8 \mathrm{~cm}$, Angle $\Theta=27^{\circ}$. This also contains same box of Thermocol outside of the G.I box. The Thermocol is having $1.5 \mathrm{~cm}$ thickness. The channel is fixed such that the water slipping on the surface of the glass will fall in this channel under the effect of gravity. A frame of fiber stick is fixed with the G.I box so that glass can rest on it. This completes the construction of the model. The holes for the inlet of water, outlet of brackish water and outlet of pure water is made as per the convenience. We have made the outlet of brackish water at right bottom of the model (seeing from front of the model), outlet of the pure water at the end of the channel and inlet at the right wall above the outlet.

\section{EXPERIMENTAL PROCEDURE}

Water to be cleaned is poured into the still to partially fill the basin. The glass cover allows the solar radiation to pass into the still, which is mostly absorbed by the black end base. This interior surface uses a blackened material to improve absorption of the sunrays.

The water begins to heat up and the moisture content of the air trapped between the water surface and the glass cover increases. The heated water vapor evaporates from the basin and condenses on the inside of the glass cover. In this process, the salts and microbes that were in the original water are left behind. Condensed water trickles down the inclined glass cover to an interior collection trough and out to a storage bottle.

Feed water should be added each day that roughly exceeds the distillate production to provide proper flushing of the basin water and to clean out excess salts left behind during the evaporation 
Process avis the still as excess to flush the basin.

\section{RESULTS ANDDISCUSSION}

Performance of still : We analyzed the performance of the still in two ways. First, we used it to purify muddy rain water collected from a puddle in the ground. The photograph below shows the water before and after purification with the still. The quality of the water is dramatically improved after purification, and it becomes crystal clear and potable. The water was tested before and after the purification. Next, we saw how effective the still was in making salty or brackish water potable. For this, we started with water that was saturated with salt, and desalinated" it with the still. All the salt was left behind in the base of the still and the output water was completely salt-free. The water was again tested for various contaminants.

The test report on the rain water sample before and after purification is listed in Table 4.3.c. Also listed are the measurements on the water sample that was desalinated by the still. The water was tested for all the contaminants that define portability as per IS:10500-1991 standards. The clear inference is that the water output from the still is potable.

\section{Readings taken for still:}

Table 1 and 2 represents the reading taken for solar still. Experiment is performed from 10:00am to 04:00pm in summer season.

The temperature of the water taken by the solar stills at gradual time difference is shown in the table 1 and table 2.

\begin{tabular}{|c|c|c|}
\hline Time & Environment Temp & Cabin Temp \\
\hline $10: 00$ AM & 54 \\
\hline $11: 00$ AM & 39 & 60.5 \\
\hline $12: 00$ PM & 41 & 64 \\
\hline $01: 00$ PM & 41 & 74 \\
\hline $02: 00$ PM & 43 & 65 \\
\hline $03: 00$ PM & 42 & 61.5 \\
\hline $04: 00$ PM & 39 & 57 \\
\hline
\end{tabular}

Table. 1. Reading for Solar Still 


\begin{tabular}{|c|c|c|}
\hline Time & $\underline{\text { Glass temp }^{\mathbf{0}} \mathbf{C}}$ & $\frac{\text { Absorber plate }}{\text { Temp } \mathbf{C}}$ \\
\hline $10: 00 \mathrm{AM}$ & 24 & 41 \\
\hline $11: 00 \mathrm{AM}$ & 24 & 43.5 \\
\hline $12: 00 \mathrm{PM}$ & 30 & 48 \\
\hline $01: 00 \mathrm{PM}$ & 36 & 55 \\
\hline $02: 00 \mathrm{PM}$ & 34.5 & 50.5 \\
\hline $03: 00 \mathrm{PM}$ & 30.5 & 48.5 \\
\hline $04: 00 \mathrm{PM}$ & 28 & 45 \\
\hline
\end{tabular}

Table.2. Reading for Solar Still of glass and absorber plate

Graph: Graph.1and 2represents the temperature variation in the solar still during six hours. The maximum temperature in the system is of $74^{\circ} \mathrm{C}$ and $55^{\circ} \mathrm{C}$ obtained at $01: 00 \mathrm{pm}$.

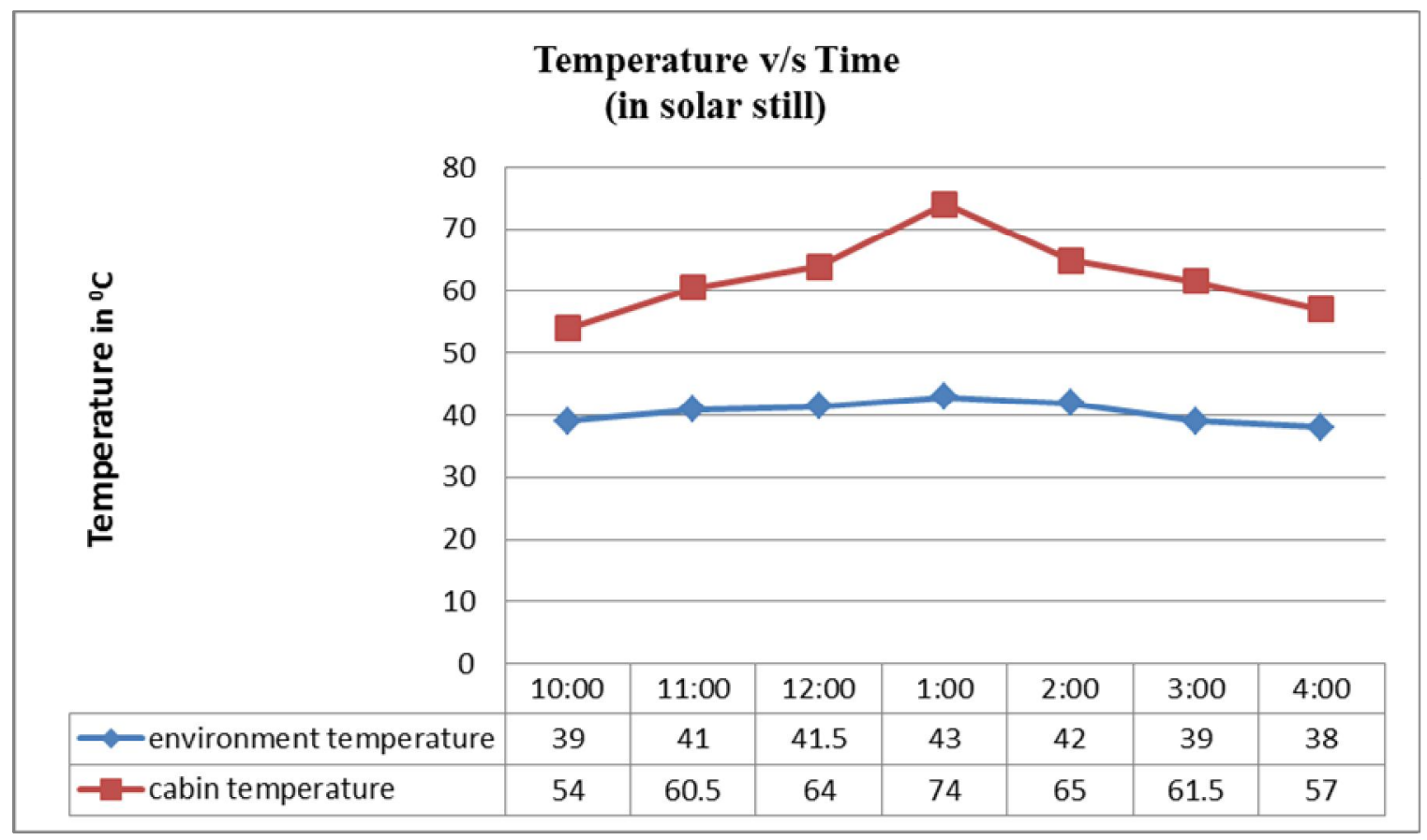

Figure . 2. Represents the temperature variation 


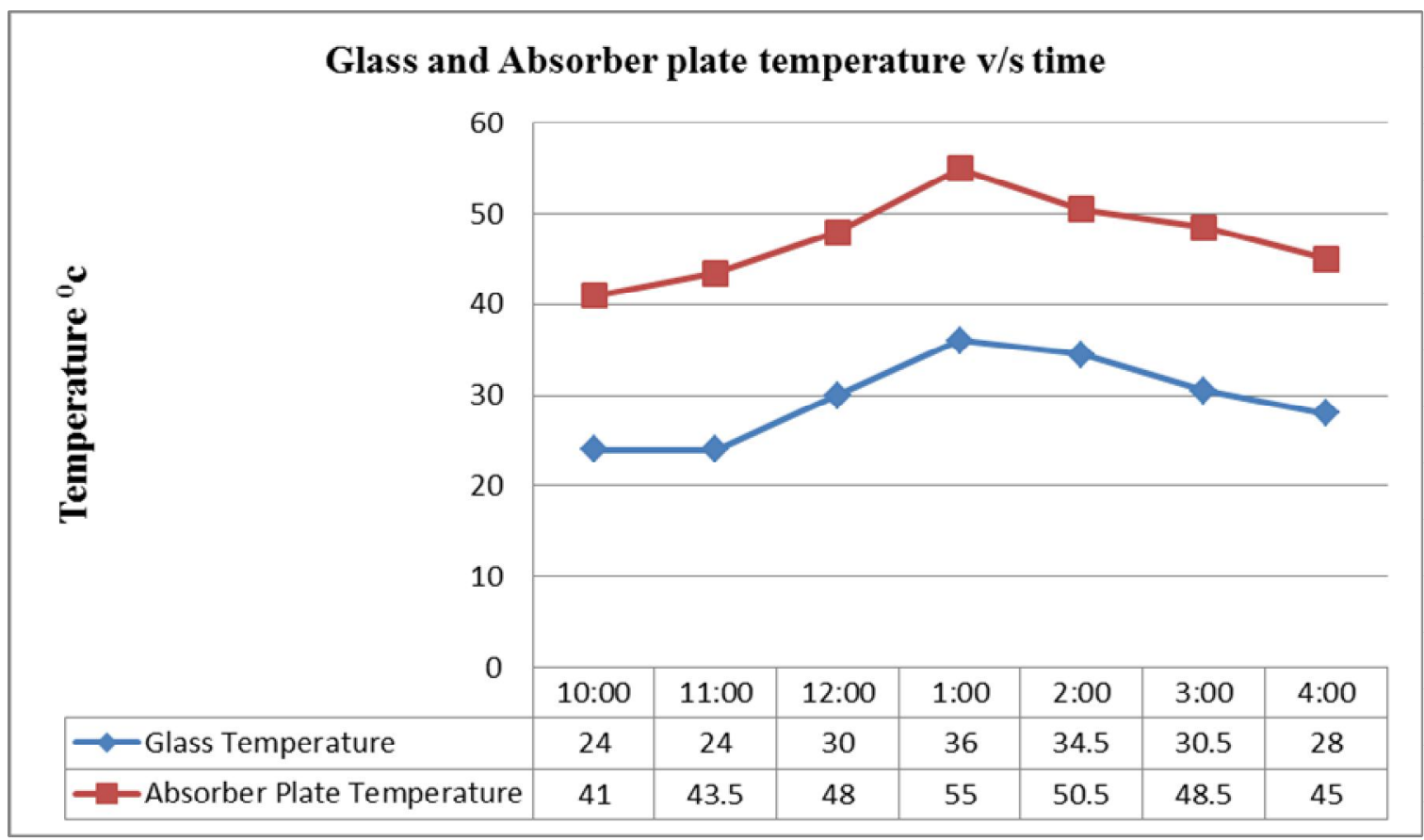

Figure .3. Represents the temperature variation

\section{CONCLUSION}

Solar energy technologies and its usage are very important and useful for the developing and under developed countries to sustain their energy needs. The use of solar energy in desalination process is one of the best applications of renewable energy. Solar still has become more popular particularly in rural areas. The solar stills are friendly to nature and eco-system. Various types and developments in solar distillation systems, theoretical analysis and future scope for research were reviewed in detail. Based on the review and discussions, the following point could be concluded.

- The condensing glass cover inclination is equal to the latitude of the place for maximum distillation.

- The total cost of the fabricated still is about $14 \%$ less than hybrid (PVT) single slope solar still. The hourly energy efficiency is also found to be highest for the same configuration and reached as high as

2.3\%. The comparative yield obtained is about 1.4 times higher than that obtained for hybrid (PVT) single slope solar still.

- Single slope passive solar still is more efficient than the double slope passive solar still.

- The thermal efficiency of double slope active solar still is lower than the thermal efficiency of double slope passive solar still.

- The energy efficiency of double slope active solar still is higher than the energy efficiency of double slope passive solar still.

- In active double effect solar still, a higher yield from the lower basin at noon is due to the high water temperature at that time.

- The hourly yield is only possible in the active mode of operation and hence commercially viable. Solar still is suited to villages and to mass production water purification. Around the world, concerns over water quality are increasing, and in special situations a solar still can provide a water supply more economically than any other method. 
The two big advantages of a solar still are that it uses low grade solar energy which is available forever and there is no greenhouse pollutant evolution as is the case with other desalination technique issuing fossil fuels. Further it can be utilized in remote places where there is no electricity and fuels.

\section{REFERENCES}

[1] Ozuomba J.O. , Edebeatu C.C., Opara M.F., Udoye M.C. and Okonkwo N.A. ---Solar Water DistillationRes.J.Chem.Sci Vol. 2(3), 64-67, March (2012).

[2] Syed Firozuddin, 1 Dr. P. V. Walke --Thermal Performance on Single Basin Solar Still with Evacuated Tubes Solar Collector-International Journal of Modern Engineering Research (IJMER) Vol.3, Issue.2, March-April. 2013 pp-1022-1025.

[3] Prof.Nilamkumar S Patel, Prof.Reepen R Shah, Mr.Nisarg M Patel, Prof.J.K.Shah, Mr.Sharvil B Bhatt--parameters on different types Of solar still--International Journal of Innovative Research in Science, Engineering and Technology Vol. 2, Issue 5, May 2013.

[4] S. Nanda kumar, a, P.P.Shantharaman,-Fabrication of solar water distillation system -International Journal Of Core Engineering \& Management (IJCEM) Volume 2, Issue 1, April 2015.

[5] RegilBadusha $\mathrm{A}^{*}$ and $\mathrm{T} \mathrm{V}$ Arjunan--PERFORMANCE ANALYSIS OF SINGLE SLOPE SOLAR STILL--Vol. 2, No. 4, October 2013

[6] Omar Badran*-- Theoretical Analysis of Solar Distillation Using Active Solar Still----Int. J. of Thermal \& Environmental Engineering Volume 3, No. 2 (2011) 113-120.

[7] Dr. Bhupendra Gupta, Tonish Kumar Mandraha,Pankaj j Edla, MohitPandya--Thermal Modeling and Efficiency of Solar Water Distillation--American Journal of Engineering Research (AJER)Volume-02,Issue-12,pp-203-213. [8] Malik MAS, Tiwari GN, Kumar A, Sodha M S. -Solar distillationll. Oxford, UK: Pergamon Press; 1982.p.8-17.

[9] Omar O Badran, Mazen M Abu-Khader. —Evaluating thermal performance of a single slope solar stilll, 